\title{
Sustainable artificial intelligence: A corporate culture perspective
}

\author{
Carmen Isensee $^{1}$ iD $\cdot$ Kai-Michael Griese $^{1} \cdot$ Frank Teuteberg $^{2}$ \\ Received: 4 June 2021 / Revised: 15 October 2021 / Accepted: 9 December 2021 / Published online: 10 January 2022 \\ (C) The Author(s) 2022
}

\begin{abstract}
In recent years, various studies have highlighted the opportunities of artificial intelligence (AI) for our society. For example, AI solutions can help reduce pollution, waste, or carbon footprints. On the other hand, there are also risks associated with the use of AI, such as increasing inequality in society or high resource consumption for computing power. This paper explores the question how corporate culture influences the use of artificial intelligence in terms of sustainable development. This type of use includes a normative element and is referred to in the paper as sustainable artificial intelligence (SAI). Based on a bibliometric literature analysis, we identify features of a sustainability-oriented corporate culture. We offer six propositions examining the influence of specific manifestations on the handling of AI in the sense of SAI. Thus, if companies want to ensure that SAI is realized, corporate culture appears as an important indicator and influencing factor at the same time.
\end{abstract}

Keywords Sustainability $\cdot \mathrm{SDG} \cdot \mathrm{AI} \cdot$ Sustainable AI $\cdot$ Organizational culture $\cdot$ Corporate culture

\section{Sustainable artificial intelligence: Eine unternehmenskulturelle Perspektive}

\section{Zusammenfassung}

In den letzten Jahren wurden in unterschiedlichen Studien die Chancen von Künstlicher Intelligenz (KI) für unsere Gesellschaft herausgearbeitet. KI-Lösungen können z. B. dabei helfen Umweltverschmutzung zu reduzieren, den KohlenstoffFußabdruck oder den Abfall zu verringern. Dem gegenüber stehen aber auch Risiken, die mit der Nutzung von KI verbunden sind, wie z.B. die Erhöhung der Ungleichheit in der Gesellschaft. Dieser Beitrag geht der Frage nach, in welcher Form die Unternehmenskultur die Nutzung von Künstlicher Intelligenz im Sinne einer nachhaltigen Entwicklung unterstützen kann. Diese Art der Nutzung beinhaltet ein normatives Element und wird in dem Beitrag als Sustainable Artificial Intelligence (SAI) bezeichnet. Auf Basis einer bibliografischen Literaturanalyse wird aufgezeigt, mit welchen Merkmalen eine nachhaltigkeitsorientierte Unternehmenskultur beschrieben werden kann. In sechs Propositionen wird zusammengefasst, welchen Einfluss diese Merkmale auf den Umgang mit KI im Sinne von SAI haben. Demnach erscheint die Unternehmenskultur für Unternehmen, die sicherstellen möchten, dass SAI realisiert wird, zugleich als wichtiger Indikator und Einflussfaktor.

Schlüsselwörter Nachhaltigkeit $\cdot \mathrm{SDG} \cdot \mathrm{KI} \cdot$ Nachhaltige KI $\cdot$ Organisationskultur $\cdot$ Unternehmenskultur

Code availability The code for textual analysis in $\mathrm{R}$ can be accessed here: https://doi.org/10.17632/hympskpm3x.1

Carmen Isensee

carmen.isensee@hs-osnabrueck.de

1 School of Business Management and Social Sciences, University of Applied Sciences Osnabrück, Albrechtstr. 30, 49076 Osnabrück, Germany

2 Department of Accounting and Information Systems, Osnabrück University, Katharinenstr. 3, 49074 Osnabrück, Germany

\section{Introduction}

Through big data and highly developed algorithms, artificial intelligence (AI) has gained great importance as an embedded element of digital systems (e.g., Duan et al. 2019; Abdulov 2020) and has changed the functioning of many business models (Strandhagen et al. 2017). In this context, more and more authors point towards the opportunities and risks of AI for achieving the Sustainable Development Goals (SDGs) formulated in the UN Agenda 2030 (e.g., 
Pedemonte 2020; Vinuesa et al. 2020) and thus highlight the effects on society (Dirican 2015; Kuo and Smith 2018; Kaplan and Haenlein 2019a) or the environment (Khakurel et al. 2018). For example, using a consensus-based expert inquiry process Vinuesa et al. (2020) conclude that AI can enable the achievement of 134 SDG subgoals but also hinder 59 goals. AI solutions can help reduce pollution, losses in production, or carbon footprint, and help address global warming (PWC 2020; Goralski and Tan 2020). Di Vaio et al. (2020) emphasize the importance of AI in the context of knowledge management systems for sustainable business models and for achieving the SDGs (in particular SDG 12). However, these authors also point out the risks that may arise from AI. For example, due to globally unequally distributed education and resources, the wealth that can be generated through AI could mainly benefit already wealthy and educated groups or individuals, thus increasing social inequalities. Furthermore, AI technologies are associated with resource depletion (Khakurel et al. 2018) and carbon emissions (Dhar 2020). Considering the opportunities and risks associated with the use of $\mathrm{AI}$ in the context of sustainability, it seems fundamentally important to re-define the socio-technical concept of AI (van Wynsberghe 2021) against the backdrop of sustainable development (Duan et al. 2019).

Past research has focused on how AI can simplify human decision making (e.g., Arinze et al. 1997; Kahneman et al. 2016; Schneider and Leyer 2019), support process optimization (e.g., Hoeschl and Barcellos 2006; D'Amico et al. 2019), or foster (sustainable) business models (e.g., Haseeb et al. 2019; Di Vaio et al. 2020), as well as the design of human-machine interaction (e.g., Klumpp 2018; Miller 2018). Less attention has so far been paid to the question of which impact people and their personal values have on the use of $\mathrm{AI}$ in the context of sustainable development (Duan et al. 2019). Within a corporate context, values are part of corporate culture. Thus, the impact of corporate culture on the use of AI appears as a major research gap. While there are many varying but no exhaustive definitions of corporate culture (Linnenluecke and Griffiths 2010) we rely on central works (e.g., Schein 2010; Cameron and Quinn 2011) to derive a working definition of corporate culture as a multi-dimensional and multi-level concept which defines the core values, assumptions, interpretations, and approaches that characterize a company and influence the behavior of its members. With the headline "Culture eats strategy for breakfast," Eckmann and Klenke (2021, p. 6) humorously describe the strong influence corporate culture can have on the realization of new corporate strategies. In this vein, various studies emphasize the importance of corporate culture for the actions of a company in the context of sustainable and digital development. For example, following Isensee et al. (2020), it can be hypothesized that corporate culture influences the use of digital technologies in companies, and thus also the use of AI, in terms of sustainable development. Barredo Arrieta et al. (2020) and Rakova et al. (2021) highlight the central role of corporate culture for reinforcing responsible AI. Liu et al. (2019) use the example of corporate culture in China and Chinese culture in general to describe that culture shapes the approach to knowledge management and AI. Similarly, based on a survey among 300 managers, Gerbert et al. (2018) identify a particular affinity for AI among the entrepreneurial culture of Chinese pioneers. Despite this initial evidence, there is currently no systematic integration of the relationship between corporate culture and AI. This article aims to close this research gap and therefore addresses the question: How can corporate culture influence the use of AI in terms of sustainable development?

Methodologically, the answer to this question is based on a bibliometric analysis of the literature from 1990 to 2021 . In the first step, a normative definition of AI in terms of sustainable development is developed (referred to as SAI). In the second step, the influence of corporate culture on AI is discussed. The article ends with a conclusion and an outlook.

\section{Sustainable artificial intelligence (SAI)}

AI can be defined as "the ability of a system to interpret external data correctly, to learn from such data, and to use those learnings to achieve specific goals and tasks through flexible adaptation" (Kaplan and Haenlein 2019b, p. 17). Given the increased awareness about potential negative effects of an unregulated AI (Bjørlo et al. 2021), Vinuesa et al. (2020) emphasize that "we are at a critical turning point for the future of AI" (p. 7). While the general definition of AI lacks any normative goal, task description, or application rules, there are more and more attempts of linking the concept of AI with normative ideas, such as those associated with the concept of sustainable development. Responsible AI is concerned with ensuring fairness, model explainability, and accountability (Barredo Arrieta et al. 2020; Rakova et al. 2021). Human-centered AI puts human aspirations, such as human rights, social participation, or environmental protection, at the center of AI design (Shneiderman 2020). For example, the Digital Policy Agenda for the Environment of the Federal Ministry for the Environment, Nature Conservation and Nuclear Safety (BMU 2019) demands a targeted use of AI to tackle environmental problems. Ethical AI introduces principles of transparency, justice and fairness, non-maleficence, responsibility, and privacy to AI design and use (Wright and Schultz 2018; Jobin et al. 2019). The normative concept of sustainable development holds the potential to combine and extend these approaches. It thus appears as a useful starting point for deriving a nor- 
Table 1 Approaches to redefine AI in terms of sustainable development

\begin{tabular}{lll}
\hline Year & Definition of sustainable development & Derived understanding of sustainable AI \\
\hline 1987 & $\begin{array}{l}\text { Sustainable development means meeting the needs of present gen- } \\
\text { erations (people; especially the poorest) without compromising the } \\
\text { ability of future generations to meet their needs (World Commission } \\
\text { on Environment and Development 1987) }\end{array}$ & $\begin{array}{l}\text { 1. SAI contributes to the realization of people's needs in the } \\
\text { present (e.g., individual fulfillment of customers' needs, es- } \\
\text { pecially the poor) without endangering the satisfaction of } \\
\text { people's needs in the future (e.g. through the exploitation of } \\
\text { natural resources) }\end{array}$ \\
$\begin{array}{ll}\text { According to the original Triple Bottom Line concept, companies } \\
\text { have a responsibility to manage their business successfully in eco- } \\
\text { nomic, social, and ecological terms (Elkington 1999) }\end{array}$ & $\begin{array}{l}\text { 2. SAI enables companies to (simultaneously) meet their eco- } \\
\text { nomic, social, and ecological responsibilities better or at all }\end{array}$ \\
$\begin{array}{l}\text { When managing the Triple Bottom Line, companies have to also } \\
\text { consider the time perspective as a fourth dimension (intergenerational } \\
\text { perspective) (Lozano 2008) }\end{array}$ & $\begin{array}{l}\text { 3. SAI enables companies to better understand the interac- } \\
\text { tion of the three sustainability dimensions through time, thus } \\
\text { considering short, long-term, and longer-term interactions } \\
\text { The guiding principle of the 2030 Agenda pursues the goal of en- } \\
\text { abling a decent life worldwide while permanently preserving the } \\
\text { natural foundations of life. With the 2030 Agenda adopted in 2015, } \\
\text { the global community under the umbrella of the United Nations com- } \\
\text { mitted to 17 global goals (SDGs) for a better future (UN 2015) }\end{array}$ & $\begin{array}{l}\text { 4he natural basis of life in the long term. To achieve this, SAI } \\
\text { supports the UN's 17 SDGs }\end{array}$ \\
\hline
\end{tabular}

mative understanding of AI, i.e., SAI, which is basically concerned with exploring AI's contribution to sustainable development. For example, Lee and Oh (2020) show that promising AI technologies for sustainable industrial development cover eleven topics, including knowledge representation, machine learning platforms, action recognition, optimization and solving, and identification technology. In applying a technology for social good perspective, Bai et al. (2021) raise the question how AI could create sustainability opportunities for micro and small enterprises. Respective overarching initiatives aiming to promote a sustainable orientation of AI in corporate practice are increasingly developing and can be joined under the umbrella term of the AI for Social Good movement (e.g., Chui et al. 2018; Tomašev et al. 2020):

- meta-initiatives: UN AI for Good, AI Commons or Climate Change AI;

- corporate funding programs: Intel AI for Social Good, Google AI for Social Good, Amazon AWS AI for Good, IBM Science for Social Good, Facebook AI for Social Good, groupelephant_-ERP, Microsoft AI for earth;

- other funding programs: Leonardo DiCaprio Foundation, Ellen MacArthur Foundation, Bill and Melinda Gates Foundation, German Federal Environmental Foundation (DBU);

- academic programs: UN Global Pulse Network, Data Science for Social Good, DFKI4planet;

- repositories: Oxford Initiative on AIxSDGs, ITU AI Repository, Plattform Lernende Systeme: KI-Landkarte Deutschland.

Apart from van Wynsberghe (2021), recent works referring to the concept of SAI fail to provide a holistic definition (e.g., Yun et al. 2016; Dhar 2020; Bjørlo et al. 2021; Dahlin 2021; Fernandez-Aller et al. 2021). For example, the working definition given by Bjørlo et al. (2021) within the contextual boundaries of online decision-making is based on the Brundtland Report (World Commission on Environment and Development 1987). Therefore, Table 1 provides an overview of four approaches most frequently discussed in literature to define sustainable development (World Commission on Environment and Development 1987; Elkington 1999; Lozano 2008; UN 2015) and the derived deeper, holistic understanding of SAI and its requirements. Therein, AI is considered as a means and an end of corporate sustainable development (van Wynsberghe 2021). Given the complexity of the sustainable development concept, AI is not considered as a system that can define what sustainable development could mean for humans.

Due to the current global importance of the SDGs for companies and the integration of the different sustainable development approaches in the 2030 Agenda, this paper links the basic understanding of AI in terms of SAI to SDG achievement. For example, Di Vaio et al. (2020) highlight the link between AI and SDG 12 (sustainable production and consumption). Accordingly, we refer to SAI when AI contributes to people being able to lead a dignified life and the natural foundations of life being permanently preserved. Consequently, in comparison to AI, SAI presents a means for sustainable development, as it is used to support the SDGs (targeted use) (e.g., Di Vaio et al. 2020; Goralski and Tan 2020; Tomašev et al. 2020; Vinuesa et al. 2020; Fernandez-Aller et al. 2021). In turn, SAI forms an end of sustainable development, as the use of AI should be organized sustainably. This includes assessing and overcoming potential negative impacts and harmful effects for society (Bjørlo et al. 2021) (application rules), such as increased waste through an accelerated use and disposal of technical devices or carbon emissions stemming from energy consumption of computing power (Khakurel et al. 2018). 
As an intermediate result, it appears that the normative concept of sustainable development provides useful to redefine AI as SAI, which now includes a targeted use and application rules as normative elements. Following up from this, it is of interest to investigate this relation more deeply within a corporate context. A problem to be faced here is that whether the potentials of AI are exploited to promote corporate sustainable development in the sense of the suggested approaches essentially depends on how the actors in the company use AI and pursue sustainable goals (e.g., sustainable business models) (Di Vaio et al. 2020). In other words, just as companies choose different approaches towards corporate sustainability (Hahn and Scheermesser 2006), they will probably choose different approaches towards AI, which makes the realization of SAI a very complex issue for which no unilateral blueprint can be provided. As corporate behavior will be determined by underlying assumptions and norms as well as other factors related to corporate culture, the following section examines the influence of specific features of sustainability-oriented corporate culture on the use of AI in the sense of SAI.

\section{Literature review: corporate culture as a driver of SAI?}

To address the research gap of a systematic integration of the relationship between corporate culture and AI, we use a bibliometric analysis of the literature review on a) sustainability-oriented corporate culture and b) SAI. We chose the period from 1990 to 2021 as a time frame to account for the rather young research trend of linking sustainability to both corporate culture and AI, thus ensuring that the paradigms underpinning the reviewed studies are mirroring the same social dynamics.

\subsection{Features of a sustainability-oriented corporate culture}

It is generally accepted that corporate culture consists of different factors, such as basic assumptions, values, norms, actions, observable artifacts, and behaviors, which can be distinguished according to their level of observability (Schein 2010; Cameron and Quinn 2011). Theoretical models relying on the dimensions of internal vs. external orientation and stability vs. control distinguish four types of culture (Cameron and Quinn 2011) or relevant cultural traits (Denison and Mishra 1995), suggesting that there is no general type of sustainability-oriented corporate culture. Despite mainly focusing on economic outcomes of corporate culture (change), these models support our investigation of a sustainability-oriented corporate culture, especially in drawing attention towards relevant features, including communication, values, and leadership. For example, in the context of fostering corporate sustainability, communication forms a relevant means within different types of corporate culture (Linnenluecke and Griffiths 2010) and the development of a culture that embraces change (Vodonick 2018). Within this paper, the major change considered is the use of AI in the sense of SAI for promoting the SDGs.

Various scholars have emphasized the need for cultural change in organizations to promote corporate sustainability (e.g., Hoffman 1993; Baumgartner 2009; Linnenluecke and Griffiths 2010; Norton et al. 2015; Vodonick 2018). This paper helps overcoming three main barriers impeding culture change towards a sustainability-oriented corporate culture. First, a unilateral understanding of corporate sustainability needs to be established among corporate executives (Hahn and Scheermesser 2006), as this determines the preferred state of the corporate culture (Cameron and Quinn 2011) as "sustainability-oriented." Second, a differentiated understanding of the single cultural features (Chen 2011) needs to be developed. Third, corporate executives need to accept culture change as a strategic task. In section 2 , we ensure

Table 2 Consideration of corporate features in conceptualizations of sustainability culture as potential influencing factors of SAI

\begin{tabular}{ll}
\hline Corporate feature & Conceptualizations of sustainability culture \\
\hline $\begin{array}{l}\text { 1. attitude, beliefs, values } \\
\text { 2. behavior }\end{array}$ & Chen (2011); Chang (2015); Ketprapakorn and Kantabutra (2019) \\
3. communication & Chen (2011); Chang (2015); Ketprapakorn and Kantabutra (2019) \\
4. collaboration & Chen (2011); Bliesner et al. (2014); Chang (2015) \\
5. ethics/norms & Chen (2011); Bliesner et al. (2014); Chang (2015); Ketprapakorn and Kantabutra (2019) \\
6. leadership/management & Chen (2011); Ketprapakorn and Kantabutra (2019) \\
7. internal capabilities & Chen (2011); Chang (2015); Wiesner et al. (2018); Ketprapakorn and Kantabutra (2019) \\
8. strategic orientation & Chen (2011); Bliesner et al. (2014); Wiesner et al. (2018); Ketprapakorn and Kantabutra (2019); Kiefer et al. (2019) \\
9. corporate structure & Chang (2015); Wiesner et al. (2018); Ketprapakorn and Kantabutra (2019) \\
\hline
\end{tabular}

Based on $N=70$ reviewed studies identified in a systematic literature review, i.e., a theoretical search query containing stemmed terms on corporate culture and environmental sustainability as well as a screening and attribution protocol containing a priori defined inclusion and exclusion criteria 
that, when engaging with SAI, corporate executives would become familiar with globally adapted approaches towards sustainable development. Within the remainder of this paper, we present potentially influential manifestations of specific features of a sustainability-oriented corporate culture for the use of AI in the sense of SAI. In the first step, to improve the understanding of sustainability-oriented corporate culture, we use a systematic literature review and an analysis approach inspired by the Preferred Reporting Items for Systematic Reviews and Meta-Analyses (PRISMA: Moher et al. 2015) ${ }^{1}$. Table 2 presents whether nine corporate features commonly found in the $N=70$ analyzed scholarly papers are represented in previous conceptualizations of sustainability culture, i.e., environmental organizational culture or green organizational identity (Chen 2011), resource culture (Bliesner et al. 2014), green organizational culture (Chang 2015), environmental sustainability culture (Wiesner et al. 2018), eco-innovation-friendly corporate culture (Kiefer et al. 2019), or the sustainability culture development framework (Ketprapakorn and Kantabutra 2019). In the next step, we analyze specific manifestations of the identified features regarding their potential influence on the adaption of AI in terms of SAI within a company. By focusing on specific features and relevant manifestations, we ensure that our results are less influenced by the fact that there is no general type of sustainability-oriented corporate culture. While the focus lies on exploring the influence of specific cultural features, the propositions we offer reveal a two-sided connection, in which (i) specific manifestations of relevant dimensions of a sustainability-oriented corporate culture could influence the use of SAI (e.g., Gerbert et al. 2018; Liu et al. 2019; Duan et al. 2019), and (ii) the use of AI can change the sustainability-orientation of corporate culture (e.g., Isensee et al. 2020; Bai et al. 2021).

\subsection{Attitudes, beliefs, and values}

Attitudes, beliefs, and values play a central role within literature on sustainability-oriented corporate culture (Isensee et al. 2020). However, especially attitudes and beliefs are underexplored in SAI literature.

According to Duan et al. (2019), corporate culture and the personal values of employees seem to condition the acceptance of SAI. Similarly, Khakurel et al. (2018) emphasize the role of values to ensure a sustainable development of AI. Overall, values are an (intra-)personal factor (Banwo and Du 2019) that motivates ecological responsibility (Williams and Schaefer 2013). For example, "ethics and

\footnotetext{
${ }_{1}^{1}$ Interested readers can receive further information on the systematic review process upon request from the authors, i.e. the full search string. The code for textual analysis in $\mathrm{R}$ is available under https://doi.org/10. 17632/hympskpm3x.1.
}

transparency" form a core value of companies with a sustainability-oriented corporate culture (Caputo et al. 2017) as well as a central principle within ethical AI (Jobin et al. 2019). As values are shared through interaction (Marsina et al. 2019), corporate culture should foster interaction between designers and users of SAI through which values aligned with the concept of sustainable development can manifest.

Attitudes determine behaviors associated with sustainable development, such as green ebusiness adoption (Masele 2019), and norms, such as a company's commitment to the environment (Singh et al. 2018). Thus, we assume that pro-environmental attitudes (Bissing-Olson et al. 2013; Yadav et al. 2018) and a positive attitude to change (Vodonick 2018) would support the adaption of SAI as a tool and standard for corporate sustainability (Upstill-Goddard et al. 2016). A positive attitude to change in the context of SAI would translate into a positive attitude towards the opportunities of SAI to support the SDGs. A regression analysis by Masele (2019) shows the influence of the three components of green attitudes, i.e., green affection, green conation, and green cognition, on green ebusiness adoption. If adapted to SAI, green affection would describe an openness to taking risks through SAI realization without perceiving SAI as threatening, as the targeted use and the consideration of SAI as an end of sustainable development might prevent undesired outcomes to some degree. Green conation would describe the intention of corporate members to adopt SAI or SAI realization behavior itself. Green cognition reflects the belief that SAI adoption enables positive environmental outcomes, such as resource savings.

Ideally, pro-environmental attitudes and values would manifest so that AI designers and users would detect, report, and correct attitude or value-behavior gaps. The detection of such gaps could be supported through pattern recognition AI technology (Lee and Oh 2020). This technology could also reveal cultural features guiding unsustainable behavior, such as beliefs, attitudes, and values that are not aligned with sustainable development.

In line with the green cognition component, which includes beliefs, the reviewed papers reveal certain contextual and self-efficacy beliefs (Kornilaki et al. 2019) with a positive influence on environmental actions. Contextual beliefs on the necessity of change and the availability of support for implementing change (Redmond et al. 2016) mirror the need to nurture a culture of change which relies upon a positive attitude towards change (Vodonick 2018). In turn, SAI offers possibilities to achieve far greater (systemic) impacts than could be achieved by individuals and thus fosters the manifestation of the self-efficacy beliefs that an individual can make a difference (Williams and Schaefer 2013). Exemplary possibilities supporting SDG13 through 
increased energy efficiency emerge from predictive maintenance facilitating an early identification of plants that do not work efficiently or environmentally friendly (Rathore and Malawalia 2021), from opportunities for modeling and thus better understanding and predicting climate change impacts (Vinuesa et al. 2020), and from the facilitation of the circular economy through the positive influence of $\mathrm{AI}$ on circular economy capabilities (Bag et al. 2021) or matching algorithms for second-hand or sharing platforms (Rathore and Malawalia 2021).

Proposition 1 Attitudes, beliefs, and values could influence the use of AI in terms of SAI if they are positively oriented towards sustainability, shared between SAI designers and users, and manifested within the company so that behavior gaps would be detected, reported, and corrected. In turn, SAI could support the detection of gaps and the formation of self-efficacy beliefs needed to establish a sustainabilityoriented corporate culture.

\subsection{Behavior (incl. communication)}

We refer to the sustainable behavior of a company as an umbrella term for habits, actions, or processes (Chen 2011; Chang 2015; Marsina et al. 2019) that positively contribute to the sustainability performance of a company. As the targeted use of SAI requires a contribution to the SDGs, the realization of SAI forms a sustainable behavior. Sustainable behavior is driven by attitudes (Bissing-Olson et al. 2013), beliefs, and values (cf. Proposition 1), especially those of owner-managers who shape corporate culture (Roxas and Coetzer 2012; Ortiz-Avram et al. 2018), as well as interpretations and norms (Chen 2011; Kornilaki et al. 2019) (cf. Proposition 4).

Communication plays a central role in previous corporate culture frameworks (Linnenluecke and Griffiths 2010; Vodonick 2018) but was only quite recently introduced into conceptualizations of sustainability culture (Wiesner et al. 2018). It appears that an effective two-way communication (Burawat 2019) between SAI designers and users or leaders and employees in which new environmental attitudes, beliefs, and values are continuously communicated (cf. Proposition 1: Wiesner et al. 2018; Ketprapakorn and Kantabutra 2019) is relevant to make employees receptive to change and have positive attitudes towards SAI (UpstillGoddard et al. 2016) as well as ensure successful collaboration (cf. Proposition 3: Marsina et al. 2019; Muñoz-Pascual et al. 2019). In summary, the communication habits could influence the use of AI in terms of SAI if they foster the receptiveness and positive attitudes of corporate members regarding the use of $\mathrm{AI}$ in the sense of SAI.

In turn, AI also influences sustainable behavior. On the one hand, AI can reinforce sustainable behavior, either by providing sustainable product or service solutions (e.g., smart cities, smart mobility: Chui et al. 2018) or by recognizing unsustainable behavior and recommending alternatives ("action recognition:" Lee and Oh 2020). On the other hand, following Tambe et al. (2019), the use of AI in a company can negatively affect sustainable behavior if it is not following sustainability principles. For example, if human resource management decisions are based on algorithms prioritizing economic outcomes, they could generate negative social outcomes for employees (e.g., unfair treatment, discrimination). Moore (2019) argues that the restructuring of workplaces or job replacements that are based on data the affected employees have no access to might increase health risks, such as anxiety. In summary, employing AI only to achieve economic goals that would hamper environmental or social goals forms an unsustainable behavior. This is likely to decrease the acceptance of AI and impedes the formation of a sustainability-orientation within corporate culture (Duan et al. 2019).

Proposition 2a A company's behavior could influence the use of AI in terms of SAI if proactive pro-environmental and two-way communication, especially between AI designers and users, are manifested as typical habits. In turn, sustainable behavior is exemplified by SAI through concrete applications.

Proactivity presents a useful distinguishing factor of sustainable behaviors. Companies that proactively engage in sustainability behavior beyond legal requirements or industry standards and challenge the status quo to follow their sustainability vision and mission can be classified as "activists" (Kornilaki et al. 2019). Accordingly, companies that are early adopters of the AI for Social Good movement (e.g., Chui et al. 2018; Tomašev et al. 2020) and thus proactively engage in employing AI to support the SDGs or challenge the status quo of an unregulated use of AI can be classified as "SAI activists." Furthermore, the distinction of daily task-related and daily proactive environmentally friendly behavior by Bissing-Olson et al. (2013) suggests that daily task-related SAI use would describe the adaption of SAI to perform work tasks sustainably, whereas daily proactive SAI use expands this by describing the initiative to adapt SAI to engage in sustainable behavior that goes beyond the scope of required work tasks. In summary, the use of AI in the sense of SAI can either be initiated by the behavior of individuals within the company as "SAI champions" (micro level) or the company as a systemic whole as "SAI activists" (macro level).

Proposition $\mathbf{2 b}$ The factor of proactivity allows for the division of a) daily task-related vs. daily proactive SAI use performed by b) individuals (SAI champions) vs. the company as a whole (SAI activists). 


\subsection{Collaboration}

Within the OCAI (Cameron and Quinn 2011), companies with a collaboration culture put a strong emphasis on individuals, including their personal development and teamwork following principles of participation and consensus. Similarly, Thomas et al. (2001) address the need for considering human and social factors in knowledge management processes. Such human relations models (Linnenluecke and Griffiths 2010) point towards a strategic involvement of internal and external stakeholders, which is key to achieving sustainable corporate practices (Caldera et al. 2019), such as the use of AI in the sense of SAI (Khakurel et al. 2018). Following Redmond et al. (2016), the entire company and its stakeholders should commit to using AI in the sense of SAI.

Internal stakeholder engagement is essential to ensure support and identify resistance to sustainable transformations (Wiesner et al. 2018), and thus for the use of AI in the sense of SAI only. External stakeholder engagement is positively related to environmental protection (BenitoHernández et al. 2016). Direct benefits associated with network participation include access to knowledge (Lewis et al. 2015) and increased sustainability innovation (Widya-Hasuti et al. 2018). For stakeholders of sustainability within the digital era, Lock and Seele (2017) introduce a classification of data generators, collectors, and utilizers. Miailhe et al. (2019) show that multi-stakeholder collaborations and new forms of public-private partnerships can define common approaches to AI in line with the SDGs. It thus appears that in order to identify solutions of SAI to support the SDGs and develop respective frameworks, companies should engage with different stakeholders through participation in networks (Ortiz-Avram et al. 2018) associated with the AI for Social Good movement or by forming new strategic sustainability alliances (Roxas and Coetzer 2012). Furthermore, human-AI collaboration emerges as a new perspective beyond human-human collaboration (Klumpp 2018; Miller 2018; Duan et al. 2019; Wang et al. 2020). In turn, Metcalf et al. (2019) indicate that AI can optimize stakeholder collaboration in terms of higher group intelligence and better decision making. Here, optimization and solving present promising technologies (Lee and Oh 2020). For example, AI technologies could identify internal stakeholders causing high pollution within a company as well as internal or external stakeholders with superior knowledge and expertise on pollution prevention and then moderate collaboration between these actors, ideally leading to a positive contribution to SDG 13 (climate action).

Proposition 3 Participative collaboration with internal and external stakeholders could influence the use of AI in terms of SAI if the collaboration goal is to collectively achieve sustainability. In turn, SAI can optimize stakeholder collaboration and adds the perspective of human-AI collaboration.

\subsection{Ethics/norms (incl. leadership)}

Following Kornilaki et al. (2019), acceptance of moral obligation is necessary to ensure the use of AI in the sense of SAI. Our definition of SAI implicitly contains a moral obligation to support the SDGs and thus provides an ethical guidance. "Green ethics" (Rodgers 2010) present an example of environmental normative pressures and emphasize the role of ethics in SAI (Khakurel et al. 2018; Wright and Schultz 2018; Barredo Arrieta et al. 2020). Accordingly, the rapid development of AI must be supported by the necessary regulatory insight and oversight for AI-based technologies (Vinuesa et al. 2020; Bai et al. 2021). After companies have formalized their acceptance of this moral obligation within sustainability norms (with a specific reference to AI use), they can derive and implement sustainability standards (Upstill-Goddard et al. 2016). Accordingly, in visualizing cultural determinants (e.g., pro-environmental values, green ethics), sustainability standards make these determinants observable (Marsina et al. 2019), providing members of the company with a standard they can refer to when assessing whether the use of $\mathrm{AI}$ is realized in the sense of SAI. Furthermore, subjective or personal as well as (perceived) social norms and the normative institutional environment influence sustainable behaviors (e.g., Banwo and Du 2019) (cf. Proposition 2a), including the use of AI in the sense of SAI. Thus, companies should formalize SAI ethics, norms, and standards.

Management and leadership play a central role within theories of corporate culture (e.g., Schein 2010; Cameron and Quinn 2011) because corporate change processes, such as the realization of SAI, require management support (e.g., Roxas and Coetzer 2012; Yadav et al. 2018), executive commitment (e.g., Coffey et al. 2013; Bliesner et al. 2014; Baranova and Paterson 2017), and the establishment of a supportive culture (Ortiz-Avram et al. 2018). Thus, if sustainability-oriented leadership becomes the norm (e.g., Chen 2011; Boiral et al. 2014; Baranova and Paterson 2017; Burawat 2019), it can support corporate culture change, especially regarding sustainable behavior (cf. Proposition 2a) (Duan et al. 2019), such as the use of AI in the sense of SAI. In turn, SAI can support sustainability-oriented leadership, i.e., sustainable decision making which examines "whether key decisions in the entrepreneurial process actually [...] take into account environmentally relevant aspects" (Muñoz 2018, p. 794).

Proposition 4 Ethics and norms could influence the use of AI in terms of SAI if they are aligned with the principles of the normative concept of sustainable development, leading 
to AI application rules. Sustainability-oriented leadership forms a relevant standard for change processes like SAI use, as it provides management support, commitment, and the development of a supportive culture. In turn, SAI can support sustainability-oriented leadership, i.e., sustainable decision making.

\subsection{Internal capabilities}

A lack of internal capabilities prevents companies from improving their environmental performance (Lewis et al. 2015; Ortiz-Avram et al. 2018) or adopting Green IT (Coffey et al. 2013), which includes SAI as an end of sustainability. In turn, sustainability-oriented corporate culture appears to improve the awareness and knowledge of environmental issues (e.g., SAI and resource use). Thereby, Leonidou et al. (2017) highlight that in order to develop an environmentally friendly mindset, it is necessary to raise awareness on environmental issues among managers. By ensuring that the normative elements of sustainable development are consequently followed through, such awareness would thus support the use of AI in the sense of SAI. A positive feedback loop can be created if action and pattern recognition (Lee and Oh 2020) are employed as promising AI approaches optimizing sustainable decision making (Duan et al. 2019) and detection of misconduct. Following different capabilities highlighted in the reviewed studies (e.g., Testa et al. 2016; Seidel-Sterzik et al. 2018; Singh et al. 2018; Kornilaki et al. 2019), SAI literacy would cover at least three issues mirroring the two perspectives of SAI as a means or end of sustainable development:

a) knowledge management regarding potential applications of AI technology to foster sustainable alternatives to current practices,

b) awareness of sustainability issues and related SAI policies, regulations, standards, and technologies, and

c) the capability to anticipate the environmental impact of technology adaption or potential negative social and environmental consequences of irresponsible or untransparent AI use.

Knowledge management emerges as a central issue in AI adaption (e.g., Liebowitz 2001; Thomas et al. 2001; Hoeschl and Barcellos 2006; Khakurel et al. 2018; Lee and Oh 2020). For the identification phase of potential AI applications for sustainable purposes (a), the potential to identify new opportunities and develop new processes (knowledge assimilation) (Jahanshahi and Brem 2017; Leonidou et al. 2017) could be of great importance. As AI technologies, new potential applications for SAI, or AI policies, regulations and standards are rapidly evolving (b), education and training (e.g., Coffey et al. 2013; Yadav et al. 2018; Muñoz-Pascual et al. 2019) become particularly important, especially regarding the anticipation of the outcomes of AI use (c). Especially managers should be properly educated on AI (Goralski and Tan 2020) and empowered to use data to make predictions, leading to an improved strategic decision-making process on sustainable development and technology adoption (Schneider and Leyer 2019). Overall, companies should rely on a diversified approach towards increased SAI literacy (Kirchherr et al. 2018), including experience, risk-taking, research and development (Kaesehage et al. 2014; Caputo et al. 2017; Johnson 2017), external training, conferences, media, and observation (e.g., Williams and Schaefer 2013; Boiral et al. 2014; Kornilaki et al. 2019). In turn, companies can use AI, especially knowledge representation technologies (Lee and Oh 2020), to assimilate knowledge and increase the ability to analyze (Wirtz and Müller 2019), especially through big data (Jarrahi 2018), as well as to share the acquired knowledge on SAI with internal and external stakeholders (Barro and Davenport 2019) (cf. Proposition 3). In this vein, Thomas et al. (2001) point out that knowledge processed with the help of $\mathrm{AI}$ is also "inextricably linked to human cognition, and the management of knowledge [...] takes place in a complexly structured social context" (p. 863).

Proposition 5 Internal capabilities, i.e., knowledge management and awareness, could influence the use of AI in terms of SAI if they provide the necessary means for increased SAI literacy. In turn, SAI can provide the means for enhancing SAI literacy and other capabilities associated with sustainable development and sharing knowledge.

\subsection{Strategic orientation}

Strategic orientation forms the most covered dimension in the studied conceptualizations of sustainability-oriented corporate culture and is also adapted as a major approach by practitioners (e.g., Leonidou et al. 2017; Marsina et al. 2019). The often-emphasized need for long-term thinking (Coffey et al. 2013) is particularly challenging for a rapidly evolving technology like AI. However, the targeted use of SAI (SDG contribution) provides a starting point for the formulation of vision and mission statements (Wiesner et al. 2018) regarding AI use. If companies strive to go beyond legal requirements (cf. Proposition $2 \mathrm{~b}$ ) and achieve continuous improvement (Baranova and Paterson 2017), for example regarding the adoption of Green IT (e.g., Testa et al. 2016; Seidel-Sterzik et al. 2018; Caldera et al. 2019), this proactivity could translate into a continuously increasing support of different SDGs through the use of AI in the sense of SAI. In turn, optimizing and solving AI technology (Lee and $\mathrm{Oh} 2020$ ) based on big data can increase the quality of forecasts for companies' long-term considerations (Nguyen Tuan et al. 2019). 
Proposition 6 Strategic orientation could influence the targeted use of AI in terms of SAI (SDG contribution) if the company persecutes long-term thinking in dealing with sustainability issues despite difficulties of anticipating potential outcomes of digital technology adoption. In turn, SAI can inform the development of a sustainability strategy through optimized forecasting.

\subsection{Corporate structure}

The reviewed literature suggests that corporate structure forms a distinct but important element for the sustainable development besides corporate culture. Marsina et al. (2019) define "a project-oriented enterprise [as] one that has a set of specific strategies, structures, and cultures" (p. 773). Upstill-Goddard et al. (2016) emphasize that the implementation of sustainability standards relies upon corporate structure, processes, and norms. According to these authors, the realization of SAI as a sustainability standard for AI use would be closely linked to the corporate structure, such as the clear definition of processes when using AI in terms of SAI. We observed that some aspects of corporate structure have low discriminatory power with respect to various characteristics of a sustainabilityoriented corporate culture, especially behavior (Proposition 2a), collaboration (Proposition 3), and management (Proposition 6). Therefore, we assume that the corporate structure provides the necessary means and conditions for SAI realization. For example, an open two-way communication structure (Upstill-Goddard et al. 2016; Jahanshahi and Brem 2017; Johnson 2017) provides the means for communicating emerging questions, uncertainties, standards, or new ideas regarding SAI use. A clear delegation of SAI tasks (Caputo et al. 2017) and the incentivization of "SAI champions" (cf. Proposition 2b) (e.g., Kaesehage et al. 2014; Baranova and Paterson 2017) provide the means for SAI-oriented collaboration and management.

Proposition 7 The company structure could influence the use of $\mathrm{AI}$ in the sense of SAI if it provides the relevant means to translate the ideal manifestations of cultural features into sustainable behavior.

\section{Discussion}

The results summarized in Table 3 suggest that specific features of a sustainability-oriented corporate culture influence the use of AI in the sense of SAI (as defined in section 2 and Table 4) in different ways and vice versa.

Table 3 Summary of main findings and propositions

\begin{tabular}{|c|c|c|c|}
\hline $\begin{array}{l}\text { Propo- } \\
\text { sition }\end{array}$ & Corporate feature & $\begin{array}{l}\text { Exemplary manifestations supporting the handling of AI in the } \\
\text { sense of a SAI }\end{array}$ & Exemplary (potential) SAI influence \\
\hline \multicolumn{4}{|c|}{ Features of sustainability-oriented corporate culture } \\
\hline \multicolumn{3}{|c|}{$\begin{array}{l}\text { RQ: How can corporate culture influence the use of artificial intelligence in terms of sustainable } \\
\text { development? }\end{array}$} & - \\
\hline 1 & $\begin{array}{l}\text { Attitudes, beliefs, } \\
\text { values }\end{array}$ & $\begin{array}{l}\text { Pro-environmental attitude and environmental values of man- } \\
\text { agers and employees }\end{array}$ & \multirow[t]{2}{*}{ Technology acceptance } \\
\hline & & Transparency as corporate value & \\
\hline $2 \mathrm{a}, \mathrm{b}$ & $\begin{array}{l}\text { Behavior (incl. } \\
\text { communication) }\end{array}$ & $\begin{array}{l}\text { Proactive pro-environmental behavior of the individual person } \\
\text { and the company as a whole }\end{array}$ & Affection of sustainable behavior \\
\hline 3 & Collaboration & $\begin{array}{l}\text { Willingness and ability to cooperate with internal and external } \\
\text { stakeholders }\end{array}$ & $\begin{array}{l}\text { Optimized stakeholder collaboration } \\
\text { New perspective: human-AI collaboration }\end{array}$ \\
\hline 4 & $\begin{array}{l}\text { Ethics/norms (incl. } \\
\text { leadership) }\end{array}$ & $\begin{array}{l}\text { Accepted environmental responsibility } \\
\text { Development of environmental standard } \\
\text { Sustainable leadership } \\
\text { AI application rules }\end{array}$ & Increased transparency \\
\hline 5 & Internal capabilities & $\begin{array}{l}\text { Environmental knowledge } \\
\text { Pro-active environmental awareness } \\
\text { SAI literacy }\end{array}$ & $\begin{array}{l}\text { Means for increased improved knowledge } \\
\text { management and pro-active awareness }\end{array}$ \\
\hline 6 & $\begin{array}{l}\text { Strategic } \\
\text { orientation }\end{array}$ & $\begin{array}{l}\text { Long-term thinking } \\
\text { Pro-active action } \\
\text { Targeted AI use }\end{array}$ & Optimized forecasting \\
\hline \multicolumn{4}{|c|}{ Other (with a mutual influence on corporate culture) } \\
\hline 7 & Corporate structure & High agility of employees and leadership in work processes & - \\
\hline
\end{tabular}


Table 4 SAI as means and ends of sustainable development

\begin{tabular}{ll}
\hline Perspective & Definition \\
\hline $\begin{array}{l}\text { SAI as means } \\
\text { of sustainable } \\
\text { development }\end{array}$ & $\begin{array}{l}\text { AI that is used to support the SDGs and thus con- } \\
\text { tributes to people being able to lead a dignified life } \\
\text { and the natural foundations of life being perma- } \\
\text { nently preserved }\end{array}$ \\
$\begin{array}{l}\text { SAI as an end } \\
\text { of sustainable } \\
\text { development }\end{array}$ & $\begin{array}{l}\text { AI use that follows sustainability principles (e.g., } \\
\text { carbon neutrality of computing power and life } \\
\text { cycle management of AI gadgets, transparent use) }\end{array}$ \\
\hline
\end{tabular}

\subsection{Core features of a sustainability-oriented corporate culture}

The first partial result of the literature analysis derives the different features of a sustainability-oriented corporate culture from existing conceptualizations. Following the number of conceptualizations considering the features, strategic orientation seems to be of greatest importance. Corporate structure cannot be clearly assigned to corporate culture, although the dependency on a sustainability-oriented corporate culture is to be assessed as high. Overall, we suggest six cultural features that could potentially influence the use of AI in the sense of SAI and are in turn affected by AI.

\subsection{Manifestations with an impact on SAI adaption}

The results suggest that certain manifestations of the investigated six features of a sustainability-oriented corporate culture are more likely to contribute to the realization of SAI (examples presented in Table 3). For example, a company that holds values related to ethics and transparency (Proposition 1) and has already developed a green code of ethics (Proposition 4) is more likely to internalize SAI ethics and transparency (Khakurel et al. 2018; Jobin et al. 2019; Barredo Arrieta et al. 2020) and thus formulate AI application rules. Proposition 3 supports the manifestation of collaboration, which forms a relevant digital future skill (Kirchherr et al. 2018). Proposition 5 suggests that the higher the awareness and the better the knowledge of sustainability issues and potential applications of SAI as a means for sustainability (SAI literacy), the more likely it is that AI will be used in the sense of SAI.

\subsection{Temporal effects}

Depending on the feature, the temporal effects of a sustainability-oriented corporate culture on SAI can be distinguished. Some features have an immediate impact (e.g., sustainable behavior), while others have a medium to longterm impact (e.g., ethics). For example, the basic underlying sustainable attitudes and values are unconscious and cannot exert a direct influence on the use of $\mathrm{AI}$ in the sense of SAI. Instead, they have a downstream effect by influencing other cultural characteristics, such as behavior. Behavior is more likely to have an immediate and direct impact on the realization of SAI, because the adaption of SAI can be embedded more easily into the structures that have evolved as the means for pro-environmental behaviors, such as responsibilities or work processes.

\subsection{Al as promoter vs. obstacle of SAI}

The results extend previous works suggesting that the use of $\mathrm{AI}$ in a company can create the basis for SAI (e.g., Metcalf et al. 2019; Wirtz and Müller 2019), for example in influencing the corporate culture that would facilitate the use of AI in the sense of SAI. Duan et al. (2019) indicate that the "acceptance and successful application of AI for decision making may result in a change of culture in organizations and in individual behavior" (p. 16). Following Barro and Davenport (2019), it would be desirable for companies to actively address the human-machine relationship to make the corporate culture smarter and to promote the use of AI in the sense of SAI. In answer to this, Proposition 5 suggests that if AI improves internal capabilities, it is likely that the company's behavior (including the use of AI) becomes more sustainable in the sense of the SDGs. However, following biases and problems of AI discussed in scholarly literature, AI could also hinder the realization of SAI under certain conditions (Tambe et al. 2019). It can be argued that there is a spectrum ranging from unsustainable AI to SAI. While a detailed discussion on the negative effects of $\mathrm{AI}$ is beyond the scope of this paper, the different sections of the sustainability spectrum of AI need to be given equal consideration in the future. Overall, unsustainable AI practices must be avoided, as they would hamper corporate culture from developing in a sustainable manner. We pointed out that unsustainable AI practices could enhance resistance against the decisions and thus reduce AI acceptance among employees or even lead to negative social outcomes, such as anxiety (Moore 2019). A human resource decision, such as the restructuring of workplaces, based on data-driven algorithms that prioritize economic outcomes because participative development approaches including different stakeholders have been neglected would form an unsustainable practice.

Overall, it can be assumed that the more sustainability-oriented the characteristics of a corporate culture, the higher the probability that the company will use $\mathrm{AI}$ in the sense of SAI. In turn, it can also be deduced across the board that the use of AI can promote a sustainability-oriented corporate culture (e.g., through increased knowledge management and forecasting). 


\section{Conclusion}

Based on a systematic literature analysis, this paper explores the question in which way sustainability-oriented corporate culture can influence the use of AI in terms of sustainable development (SAI in short). The motivation for this is the potential of AI to influence sustainable development positively or negatively and the lack of a normative guide for AI use. First, this paper contributes to the AI for Social Good debate by providing a normative definition of SAI as a means and end to sustainability with a targeted use and application rules derived from prominent approaches towards sustainable development, including the SDGs. Second, following Barro and Davenport (2019), this paper demonstrates that the opportunity to use AI in terms of SAI depends on the ability of a company and its corporate culture to innovate AI in terms of sustainable development through its human capital. A first theoretical frame of reference is offered for the two-sided connection between features of sustainability-oriented corporate culture and the use of AI in the sense of SAI. Overall, the presented evidence suggests a strong mutual influence. As practical implications, a variety of starting points can be derived for companies that wish to apply AI in the sense of SAI. Decision-makers can analyze the sustainability-orientation of the corporate culture and check whether the prerequisites for SAI are in place. Therefore, they can draw from the six propositions which systematically demonstrate the potential influence of specific manifestations of cultural features derived from existing concepts of sustainability-oriented corporate culture.

Future research avenues emerge from the propositions and the limitations of this paper. There is a need for further research regarding (i) the conceptual delimitation between $\mathrm{SAI}$, responsible $\mathrm{AI}$, ethical $\mathrm{AI}$, and human-centered $\mathrm{AI}$, (ii) the influence of SAI on corporate culture and corporate structures, (iii) a validation of the effect of the different cultural features on SAI, and (iv) an investigation of the effects of SAI on sustainability. Empirical studies and longitudinal case studies (e.g., good practice cases) would allow for an in-depth investigation of the development phases of SAI, including the identification of cultural manifestations with the most significant and strongest influence based on widely accepted corporate culture concepts and assessment tools.

Acknowledgements We would like to thank the two independent reviewers for their feedback which we believe has enabled us to substantially improve the paper.

Author Contribution All authors contributed to the review article. Literature search and analysis were performed by Carmen Isensee and Kai-Michael Griese. The first draft of the manuscript was written by Carmen Isensee and Kai-Michael Griese. All authors critically revised the work and read and approved the final manuscript.
Funding This work was supported by the German Federal Environmental Foundation (DBU) [grant number 34937/01].

Funding Open Access funding enabled and organized by Projekt DEAL.

Conflict of interest C. Isensee, K.-M. Griese and F. Teuteberg declare that they have no competing financial interests or personal relationships that could have appeared to influence the work reported in this paper.

Open Access This article is licensed under a Creative Commons Attribution 4.0 International License, which permits use, sharing, adaptation, distribution and reproduction in any medium or format, as long as you give appropriate credit to the original author(s) and the source, provide a link to the Creative Commons licence, and indicate if changes were made. The images or other third party material in this article are included in the article's Creative Commons licence, unless indicated otherwise in a credit line to the material. If material is not included in the article's Creative Commons licence and your intended use is not permitted by statutory regulation or exceeds the permitted use, you will need to obtain permission directly from the copyright holder. To view a copy of this licence, visit http://creativecommons.org/licenses/by/4. $0 /$.

\section{References}

Abdulov R (2020) Artificial intelligence as an important factor of sustainable and crisis-free economic growth. Procedia Comput Sci 169:468-472. https://doi.org/10.1016/j.procs.2020.02.223

Arinze B, Kim S-L, Anandarajan M (1997) Combining and selecting forecasting models using rule based induction. Comput Oper Res 24:423-433. https://doi.org/10.1016/s0305-0548(96)00062-7

Bag S, Pretorius JHC, Gupta S, Dwivedi YK (2021) Role of institutional pressures and resources in the adoption of big data analytics powered artificial intelligence, sustainable manufacturing practices and circular economy capabilities. Technol Forecast Soc Change 163:120420. https://doi.org/10.1016/j.techfore.2020. 120420

Bai C, Quayson M, Sarkis J (2021) COVID-19 Pandemic Digitization Lessons for Sustainable Development of Micro-and Small-Enterprises. Sustain Prod Consum. https://doi.org/10.1016/j.spc.2021. 04.035

Banwo AO, Du J (2019) Workplace pro-environmental behaviors in small and medium-sized enterprises: an employee level analysis. J Glob Entrepr Res 9:179. https://doi.org/10.1186/s40497-0190156-4

Baranova P, Paterson F (2017) Environmental capabilities of small and medium sized enterprises: towards transition to a low carbon economy in the east midlands. Local Econ 32:835-853. https:// doi.org/10.1177/0269094217744494

Barredo Arrieta A, Díaz-Rodríguez N, Del Ser J, Bennetot A, Tabik S, Barbado A, Garcia S, Gil-Lopez S, Molina D, Benjamins R, Chatila R, Herrera F (2020) Explainable Artificial Intelligence (XAI): Concepts, taxonomies, opportunities and challenges toward responsible AI. Inf Fusion 58:82-115. https://doi.org/10. 1016/j.inffus.2019.12.012

Barro S, Davenport TH (2019) People and machines: partners in innovation. MIT Sloan Manage Rev 60(4):22-28

Baumgartner RJ (2009) Organizational culture and leadership: preconditions for the development of a sustainable corporation. Sustain Dev 17:102-113. https://doi.org/10.1002/sd.405

Benito-Hernández S, Platero-Jaime M, Esteban-Sánchez P (2016) The influence of cooperative relations of small businesses on environmental protection intensity. Business Ethics Eur Rev 25:416-439. https://doi.org/10.1111/beer.12126

Bissing-Olson MJ, Iyer A, Fielding KS, Zacher H (2013) Relationships between daily affect and pro-environmental behavior at work: the 
moderating role of pro-environmental attitude. J Organiz Behav 34:156-175. https://doi.org/10.1002/job.1788

Bjørlo L, Moen Ø, Pasquine M (2021) The role of consumer autonomy in developing sustainable AI: a conceptual framework. Sustainability 13:2332. https://doi.org/10.3390/su13042332

Bliesner A, Liedtke C, Rohn H (2014) Resource efficiency and culture-workplace training for small and medium-sized enterprises. Sci Total Environ 481:645-648. https://doi.org/10.1016/j. scitotenv.2013.11.053

BMU (2019) The BMU's key points for a digital policy agenda for the environment. https://www.bmu.de/en/download/the-bmus-keypoints-for-a-digital-policy-agenda-for-the-environment. Accessed 01 July 2020

Boiral O, Baron C, Gunnlaugson O (2014) Environmental leadership and consciousness development: a case study among Canadian SMEs. J Bus Ethics 123:363-383. https://doi.org/10.1007/ s10551-013-1845-5

Burawat P (2019) The relationships among transformational leadership, sustainable leadership, lean manufacturing and sustainability performance in Thai SMEs manufacturing industry. IJQRM 36:1014-1036. https://doi.org/10.1108/IJQRM-09-2017-0178

Caldera HTS, Desha C, Dawes L (2019) Evaluating the enablers and barriers for successful implementation of sustainable business practice in "lean" SMEs. J Clean Prod 218:575-590. https://doi. org/10.1016/j.jclepro.2019.01.239

Cameron KS, Quinn RE (2011) Diagnosing and changing organizational culture: based on the competing values framework, 3rd edn. Jossey-Bass, San Francisco

Caputo F, Veltri S, Venturelli A (2017) A conceptual model of forces driving the introduction of a sustainability report in SMEs: evidence from a case study. IBR 10:39. https://doi.org/10.5539/ibr. v10n5p39

Chang CH (2015) Proactive and reactive corporate social responsibility: antecedent and consequence. Manag Decis 53:451-468. https://doi.org/10.1108/MD-02-2014-0060

Chen YS (2011) Green organizational identity: sources and consequence. Manag Decis 49:384-404. https://doi.org/10.1108/ 00251741111120761

Chui KT, Lytras MD, Visvizi A (2018) Energy sustainability in smart cities: artificial intelligence, smart monitoring, and optimization of energy consumption. Energies 11:2869. https://doi.org/10. 3390/en11112869

Chui M, Harrysson M, Manyika J, Roberts R, Chung R, Nel P, van Heteren A (2018) Applying artificial intelligence for social good. McKinsey \& Company. https://www.mckinsey.com/ / media/mckinsey/featured\%20insights/artificial\%20intelligence/ applying\%20artificial\%20intelligence $\% 20$ for $\% 20$ social $\% 20 \mathrm{good} /$ mgi-applying-ai-for-social-good-discussion-paper-dec-2018. ashx. Accessed 15 April 2021

Coffey P, Tate M, Toland J (2013) Small business in a small country: attitudes to "Green" IT. Inf Syst Front 15:761-778. https://doi. org/10.1007/s10796-013-9410-4

Dahlin E (2021) Mind the gap! On the future of AI research. Hum Soc Sci Commun. https://doi.org/10.1057/s41599-021-00750-9

D’Amico B, Myers RJ, Sykes J, Voss E, Cousins-Jenvey B, Fawcett W, Richardson S, Kermani A, Pomponi F (2019) Machine learning for sustainable structures: a call for data. Structures 19:1-4. https://doi.org/10.1016/j.istruc.2018.11.013

Denison DR, Mishra AK (1995) Toward a theory of organizational culture and effectiveness. Organ Sci 6(2) 204-223. https://doi.org/10. 1287/orsc.6.2.204

Dhar P (2020) The carbon impact of artificial intelligence. Nat Mach Intell 2:423-425. https://doi.org/10.1038/s42256-020-0219-9

Di Vaio A, Palladino R, Hassan R, Escobar O (2020) Artificial intelligence and business models in the sustainable development goals perspective: a systematic literature review. J Bus Res 121:283-314. https://doi.org/10.1016/j.jbusres.2020.08.019
Dirican C (2015) The Impacts of Robotics, Artificial Intelligence On Business and Economics. Procedia Soc Behav Sci 195:564-573. https://doi.org/10.1016/j.sbspro.2015.06.134

Duan Y, Edwards JS, Dwivedi YK (2019) Artificial intelligence for decision making in the era of Big Data-evolution, challenges and research agenda. Int J Inf Manage 48:63-71. https://doi.org/ 10.1016/j.ijinfomgt.2019.01.021

Eckmann D, Klenke U (2021 an) Branding und Strategien der Deutschen Telekom. 47. Jahrestagung der Arbeitsgemeinschaft für Marketing, Hochschule Bonn-Rhein-Sieg, Sankt Augustin, 22. bis 23. April 2021 (AfM-Dialog 2021 - Dynamik in Markt and Lehre)

Elkington J (1999) Cannibals with forks: triple bottom line of 21st century business. Capstone Publishing,

Fernandez-Aller C, de Velasco AF, Manjarres A, Pastor-Escuredo D, Pickin S, Criado JS, Ausin T (2021) An Inclusive and Sustainable Artificial Intelligence Strategy for Europe Based on Human Rights. IEEE Tech Soc Mag 40(1):46-54. https://doi.org/10.1109/ MTS.2021.3056283

Gerbert P, Reeves M, Ransbotham S, Kiron D, Spira M (2018) Global competition with AI in business: how China differs. MIT Sloan Manage Rev

Goralski MA, Tan TK (2020) Artificial intelligence and sustainable development. Int J Manag Educ 18:100330. https://doi.org/10.1016/ j.ijme.2019.100330

Hahn T, Scheermesser M (2006) Approaches to corporate sustainability among German companies. Corp Soc Responsib Environ Mgmt 13:150-165. https://doi.org/10.1002/csr.100

Haseeb M, Hussain HI, Ślusarczyk B, Jermsittiparsert K (2019) Industry 4.0: a solution towards technology challenges of sustainable business performance. Soc Sci 8:154. https://doi.org/10.3390/ socsci 8050154

Hoeschl HC, Barcellos V (2006) Artificial intelligence and knowledge management. In: Bramer M (ed) Artificial intelligence in theory and practice. IFIP AI 2006. IFIP international federation for information processing, vol 217. Springer, Boston

Hoffman AJ (1993) The importance of fit between individual values and organisational culture in the greening of industry. Bus Strat Env 2:10-18. https://doi.org/10.1002/bse.3280020402

Isensee C, Teuteberg F, Griese K-M, Topi C (2020) The relationship between organizational culture, sustainability, and digitalization in SMEs: a systematic review. J Clean Prod 275:122944. https:// doi.org/10.1016/j.jclepro.2020.122944

Jahanshahi AA, Brem A (2017) Sustainability in SMEs: top management teams behavioral integration as source of innovativeness. Sustainability 9:1899. https://doi.org/10.3390/su9101899

Jarrahi MH (2018) Artificial intelligence and the future of work: human-AI symbiosis in organizational decision making. Bus Horiz 61:577-586. https://doi.org/10.1016/j.bushor.2018.03.007

Jobin A, Ienca M, Vayena E (2019) The global landscape of AI ethics guidelines. Nat Mach Intell 1(9):389-399. https://doi.org/10. 1038/s42256-019-0088-2

Johnson MP (2017) Knowledge acquisition and development in sustainability-oriented small and medium-sized enterprises: exploring the practices, capabilities and cooperation. J Clean Prod 142:3769-3781. https://doi.org/10.1016/j.jclepro.2016.10.087

Kaesehage K, Leyshon M, Caseldine C (2014) Communicating climate change-Learning from business: challenging values, changing economic thinking, innovating the low carbon economy. Fennia 192:81-99. https://doi.org/10.11143/40867

Kahneman D, Rosenfield AM, Gandhi L, Blaser T (2016) Noise: How to overcome the high, hidden cost of inconsistent decision making. Harv Bus Rev 94(10):38-46

Kaplan A, Haenlein M (2019a) Digital transformation and disruption: On big data, blockchain, artificial intelligence, and other things. Bus Horiz 62:679-681. https://doi.org/10.1016/j.bushor.2019.07. 001

Kaplan AM, Haenlein M (2019b) Siri, Siri, in my hand: Who's the fairest in the land? On the interpretations, illustrations, and impli- 
cations of artificial intelligence. Bus Horiz 62:15-25. https://doi. org/10.1016/j.bushor.2018.08.004

Ketprapakorn N, Kantabutra S (2019) Culture development for sustainable SMEs: toward a behavioral theory. Sustainability 11:2629. https://doi.org/10.3390/su11092629

Khakurel J, Penzenstadler B, Porras J, Knutas A, Zhang W (2018) The rise of artificial intelligence under the lens of sustainability. Technologies 6(4):100. https://doi.org/10.3390/technologies6040100

Kiefer CP, Del Río González P, Carrillo-Hermosilla J (2019) Drivers and barriers of eco-innovation types for sustainable transitions: a quantitative perspective. Bus Strat Env 28:155-172. https://doi. org/10.1002/bse. 2246

Kirchherr J, Klier J, Lehmann-Brauns C, Winde M (2018) Future Skills: Welche Kompetenzen in Deutschland fehlen. Stifterverband, McKinsey\&Company. https://stifterverband.org/medien/ future-skills-welche-kompetenzen-in-deutschland-fehlen. Acessed May 2021.

Klumpp M (2018) Automation and artificial intelligence in business logistics systems: human reactions and collaboration requirements. Int J Logist Res Appl 21:224-242. https://doi.org/10. 1080/13675567.2017.1384451

Kornilaki M, Thomas R, Font X (2019) The sustainability behaviour of small firms in tourism: the role of self-efficacy and contextual constraints. J Sustain Tour 27:97-117. https://doi.org/10.1080/ 09669582.2018 .1561706

Kuo TC, Smith S (2018) A systematic review of technologies involving eco-innovation for enterprises moving towards sustainability. J Clean Prod 192:207-220. https://doi.org/10.1016/j.jclepro. 2018.04.212

Lee HJ, Oh H (2020) A study on the deduction and diffusion of promising artificial intelligence technology for sustainable industrial development. Sustainability 12:5609. https://doi.org/10. 3390/su12145609

Leonidou LC, Christodoulides P, Kyrgidou LP, Palihawadana D (2017) Internal drivers and performance consequences of small firm green business strategy: the moderating role of external forces. J Bus Ethics 140:585-606. https://doi.org/10.1007/s10551-0152670-9

Lewis KV, Cassells S, Roxas H (2015) SMes and the potential for a collaborative path to environmental responsibility. Bus Strat Env 24:750-764. https://doi.org/10.1002/bse.1843

Liebowitz J (2001) Knowledge management and its link to artificial intelligence. Expert Syst Appl 20:1-6. https://doi.org/10.1016/ s0957-4174(00)00044-0

Linnenluecke MK, Griffiths A (2010) Corporate sustainability and organizational culture. J World Bus 45:357-366. https://doi.org/10. 1016/j.jwb.2009.08.006

Liu Y, Chan C, Zhao C, Liu C (2019) Unpacking knowledge management practices in China: do institution, national and organizational culture matter? JKM 23:619-643. https://doi.org/10.1108/ JKM-07-2017-0260

Lock I, Seele P (2017) Theorizing stakeholders of sustainability in the digital age. Sustain Sci 12:235-245. https://doi.org/10.1007/ s11625-016-0404-2

Lozano R (2008) Envisioning sustainability three-dimensionally. J Clean Prod 16:1838-1846. https://doi.org/10.1016/j.jclepro. 2008.02.008

Marsina S, Hamranova A, Hrivikova T, Bolek V, Zagorsek B (2019) How can project orientation contribute to pro-environmental behavior in private organizations in Slovakia. J Clean Prod 231:772-782. https://doi.org/10.1016/j.jclepro.2019.05.186

Masele JJ (2019) Top management team's green entrepreneurial attitude and its influence on green ebusiness adoption: empirical evidence from tour operators in Tanzania. Small Enterp Res 26:78-104. https://doi.org/10.1080/13215906.2019.1572030

Metcalf L, Askay DA, Rosenberg LB (2019) Keeping humans in the loop: pooling knowledge through artificial swarm intelligence to improve business decision making. Calif Manage Rev 61:84-109. https://doi.org/10.1177/0008125619862256

Miailhe N, Hodes C, Jain A, Iliadis N, Alanoca S, Png J (2019) AI for sustainable development goals. Delphi Interdiscip Rev Emerg Technol 2:207-216. https://doi.org/10.21552/delphi/2019/4/10

Miller SM (2018) AI: Augmentation, more so than automation. Asian Manag Insights 5:1-20

Moher D, Shamseer L, Clarke M, Ghersi D, Liberati A, Petticrew M, Shekelle P, Stewart LA (2015) Preferred reporting items for systematic review and meta-analysis protocols (PRISMA-P) 2015 statement. Syst Rev 4:1. https://doi.org/10.1186/2046-4053-4-1

Moore PV (2019) OSH and the future of work: benefits and risks of artificial intelligence tools in workplaces. In: Duffy VG (ed) Digital human modeling and applications in health, safety, ergonomics and risk management. Human body and motion. Springer, Cham, pp 292-315 https://doi.org/10.1007/978-3-030-22216-1_22

Muñoz P (2018) A cognitive map of sustainable decision-making in entrepreneurship. Int J Entrepr Behav Res 24:787-813. https:// doi.org/10.1108/IJEBR-03-2017-0110

Muñoz-Pascual L, Curado C, Galende J (2019) The triple bottom line on sustainable product innovation performance in SMEs: a mixed methods approach. Sustainability 11:1689. https://doi.org/ $10.3390 / \mathrm{su} 11061689$

Nguyen Tuan M, Nguyen TN, Le Tuan L (2019) Applying a mindfulness-based reliability strategy to the Internet of things in healthcare - a business model in the Vietnamese market. Technol Forecast Soc Change 140:54-68. https://doi.org/10.1016/j. techfore.2018.10.024

Norton TA, Zacher H, Ashkanasy NM (2015) Pro-environmental organizational culture and climate. In: Robertson JL, Barling J (eds) The psychology of green organizations. Oxford University Press, Oxford, pp 322-348

Ortiz-Avram D, Domnanovich J, Kronenberg C, Scholz M (2018) Exploring the integration of corporate social responsibility into the strategies of small- and medium-sized enterprises: a systematic literature review. J Clean Prod 201:254-271. https://doi.org/10. 1016/j.jclepro.2018.08.011

Pedemonte C (2020) AI for Sustainability: an overview of AI and the SDGs to contribute to the European policy-making. https://ec. europa.eu/futurium/en/system/files/ged/vincent-pedemonte_aifor-sustainability_0.pdf. Accessed 29 Mar 2021

PWC (PriceWaterCoopers) (2020) How AI can enable a sustainable future. https://www.pwc.de/de/nachhaltigkeit/how-ai-can-enablea-sustainable-future.pdf. Accessed 29 Mar 2021

Rakova B, Yang J, Cramer H, Chowdhury R (2021) Where responsible AI meets reality. Proc ACM Hum Comput Interact 5:1-23. https:// doi.org/10.1145/3449081

Rathore AS, Malawalia P (2021) Deploying artificial intelligence for circular economy and its link with sustainable development goals. Int J Policy Sci Law 1:1975-2003

Redmond J, Cox WJ, Curtis J, Kirk-Brown A, Walker B (2016) Beyond business as usual: how (and why) the habit discontinuity hypothesis can inform SME engagement in environmental sustainability practices. Australas J Environ Manag 23:426-442. https://doi.org/ 10.1080/14486563.2016.1188424

Rodgers C (2010) Sustainable entrepreneurship in SMEs: a case study analysis. Corp Soc Responsib Environ Mgmt 17:125-132. https:// doi.org/10.1002/csr.223

Roxas B, Coetzer A (2012) Institutional environment, managerial attitudes and environmental sustainability orientation of small firms. J Bus Ethics 111:461-476. https://doi.org/10.1007/s10551-0121211-Z

Schein EH (2010) Organizational culture and leadership, 2nd edn. Jossey-Bass, San Francisco

Schneider S, Leyer M (2019) Me or information technology? Adoption of artificial intelligence in the delegation of personal strategic decisions. Manag Decis Econ 40:223-231. https://doi.org/10.1002/ mde. 2982 
Seidel-Sterzik H, McLaren S, Garnevska E (2018) Effective life cycle management in SMEs: use of a sector-based approach to overcome barriers. Sustainability 10:359. https://doi.org/10.3390/ su10020359

Shneiderman B (2020) Human-centered artificial intelligence: three fresh ideas. AIS Trans Human Comput Interact. https://doi.org/ 10.17705/1thci.00131

Singh MP, Chakraborty A, Roy M (2018) Developing an extended theory of planned behavior model to explore circular economy readiness in manufacturing MSMEs, India. Resour Conserv Recycl 135:313-322. https://doi.org/10.1016/j.resconrec.2017.07.015

Strandhagen JO, Vallandingham LR, Fragapane G, Strandhagen JW, Stangeland ABH, Sharma N (2017) Logistics 4.0 and emerging sustainable business models. Adv Manuf 5:359-369. https://doi. org/10.1007/s40436-017-0198-1

Tambe P, Cappelli P, Yakubovich V (2019) Artificial intelligence in human resources management: challenges and a path forward. Calif Manage Rev 61:15-42. https://doi.org/10.1177/ 0008125619867910

Testa F, Gusmerottia NM, Corsini F, Passetti E, Iraldo F (2016) Factors affecting environmental management by small and micro firms: the importance of entrepreneurs' attitudes and environmental investment. Corp Soc Responsib Environ Mgmt 23:373-385. https://doi.org/10.1002/csr.1382

Thomas JC, Kellogg WA, Erickson T (2001) The knowledge management puzzle: Human and social factors in knowledge management. IBM Syst J 40:863-884. https://doi.org/10.1147/sj.404. 0863

Tomašev N, Cornebise J, Hutter F, Mohamed S, Picciariello A, Connelly B, Belgrave DCM, Ezer D, van der Haert FC, Mugisha F, Abila G, Arai H, Almiraat H, Proskurnia J, Snyder K, OtakeMatsuura M, Othman M, Glasmachers T, Wever WD, Teh YW, Khan ME, Winne RD, Schaul T, Clopath C (2020) AI for social good: unlocking the opportunity for positive impact. Nat Commun 11:2468. https://doi.org/10.1038/s41467-020-15871-z

UN (2015) Transforming our world: the 2030 Agenda for Sustainable Development. United Nations General Assembly. https://sdgs.un. org/2030agenda. Accessed June 2021

Upstill-Goddard J, Glass J, Dainty A, Nicholson I (2016) Implementing sustainability in small and medium-sized construction firms. Eng Constr Archit Manag 23:407-427. https://doi.org/10.1108/ ECAM-01-2015-0015

Vinuesa R, Azizpour H, Leite I, Balaam M, Dignum V, Domisch S, Felländer A, Langhans SD, Tegmark M, Fuso Nerini F (2020) The role of artificial intelligence in achieving the sustainable de- velopment goals. Nat Commun 11:233. https://doi.org/10.1038/ s41467-019-14108-y

Vodonick J (2018) The key to organizational sustainability: nurturing a culture of change. Syst Res Behav Sci 35:458-468. https://doi. org/10.1002/sres.2539

Wang D, Churchill E, Maes P, Fan X, Shneiderman B, Shi Y, Wang Q (2020) From human-human collaboration to human-AI collaboration. In: Bernhaupt R, Mueller FF, Verweij D, Andres J, McGrenere J, Cockburn A, Avellino I, Goguey A, Bjørn P, Zhao S, Samson BP, Kocielnik R (eds) Extended abstracts of the $2020 \mathrm{CHI}$ conference on human factors in computing systems. ACM, New York, pp 1-6

Widya-Hasuti A, Mardani A, Streimikiene D, Sharifara A, Cavallaro F (2018) The role of process innovation between firm-specific capabilities and sustainable innovation in SMEs: empirical evidence from Indonesia. Sustainability 10:2244. https://doi.org/10.3390/ su10072244

Wiesner R, Chadee D, Best P (2018) Managing change toward environmental sustainability: a conceptual model in small and medium enterprises. Organ Environ 31:152-177. https://doi.org/10.1177/ 1086026616689292

Williams S, Schaefer A (2013) Small and medium-sized enterprises and sustainability: managers' values and engagement with environmental and climate change issues. Bus Strat Env 22:173-186. https://doi.org/10.1002/bse.1740

Wirtz BW, Müller WM (2019) An integrated artificial intelligence framework for public management. Public Manag Rev 21:1076-1100. https://doi.org/10.1080/14719037.2018.1549268

World Commission on Environment and Development (1987) Our common future. Oxford University Press, Oxford

Wright SA, Schultz AE (2018) The rising tide of artificial intelligence and business automation: developing an ethical framework. Bus Horiz 61:823-832. https://doi.org/10.1016/j.bushor.2018.07.001

van Wynsberghe A (2021) Sustainable AI: AI for sustainability and the sustainability of AI. Ai Ethics 1:213-218. https://doi.org/10. 1007/s43681-021-00043-6

Yadav N, Gupta K, Rani L, Rawat D (2018) Drivers of sustainability practices and SMEs: a systematic literature review. EJSD. https:// doi.org/10.14207/ejsd.2018.v7n4p531

Yun JH, Lee D, Ahn H, Park K, Yigitcanlar T (2016) Not deep learning but autonomous learning of open innovation for sustainable artificial intelligence. Sustainability 8(8):797. https://doi.org/10.3390/ su8080797 